\title{
Review: antidepressants are effective for clinical unexplained physical symptoms and syndromes
}

O'Malley PG, Jackson JL, Santoro J, et al. Antidepressant therapy for unexplained symptoms and symptom syndromes. J Fam Pract 1999 Dec;48:980-90.

QUESTION: In adults who have medically unexplained physical symptoms (MUPS), do

Source of funding: in part, the MacArthur Foundation Initiative on Depression in Primary Care.

For correspondence: Dr P G O'Malley,

Department of

Medicine, Walter Reed Army Medical Center, 6900 Georgia Avenue,

Washington, $D C$ 20307-5001, USA

Fax +1202782

7363

Abstract and commentary also

appears in

Evidence-Based

Medicine. antidepressants improve outcomes?

\section{Data sources}

Studies were identified by searching Medline (1966-98), PsycLIT (1974-98), EMBASE/Excerpta Medica (197498), the Cochrane Library, the Federal Research in Progress database, and bibliographies of relevant articles.

\section{Study selection}

2 reviewers independently selected studies that were randomised controlled trials (RCTs) (including crossover trials), involved adults with MUPS, compared antidepressants with placebo or a non-antidepressant intervention, reported measurable outcomes, and were published in English. Disagreements were resolved by consensus.
Antidepressants $v$ placebo for unexplained symptoms or syndromest

\begin{tabular}{|c|c|c|c|c|c|c|}
\hline \multirow{2}{*}{$\begin{array}{l}\text { Symptoms or } \\
\text { syndromes }\end{array}$} & \multicolumn{4}{|c|}{$\begin{array}{l}\text { Number of RCTs for each type } \\
\text { of antidepressant }\end{array}$} & \multirow{2}{*}{$\begin{array}{l}\text { Mean quality } \\
\text { score }\end{array}$} & \multirow{2}{*}{$\begin{array}{l}\text { Pooled OR (95\% } \\
\text { Cl) } \ddagger\end{array}$} \\
\hline & TCA & SSRI & Anti-S & Other & & \\
\hline Chronic headache & 21 & 8 & 23 & - & 4.6 & 3.4 (2.7 to 4.4$)$ \\
\hline Fibromyalgia & 12 & 4 & - & 3 & 5.8 & 5.1 (3.1 to 8.5$)$ \\
\hline $\begin{array}{c}\text { Functional GI } \\
\text { disorders }\end{array}$ & 11 & - & 2 & 1 & 4.1 & 4.4 (2.5 to 7.7$)$ \\
\hline Idiopathic pain & 8 & 2 & 2 & - & 4.2 & 2.0 (1.4 to 2.8$)$ \\
\hline Tinnitus & 2 & - & - & - & 4.0 & - \\
\hline Chronic fatigue & - & 2 & - & - & 4.0 & - \\
\hline All & 56 & 17 & 28 & 3 & 4.8 & 3.4 (2.6 to 4.3$)$ \\
\hline
\end{tabular}

†Anti-S=anti-serotonin; $\mathrm{Gl}=$ gastrointestinal; $\mathrm{OR}=$ odds ratio; $\mathrm{RCTs}=$ randomised controlled trials; $\mathrm{SSR}=$ =selective serotonin reuptake inhibitor; TCA=tricyclic antidepressant. Median follow up was 9 weeks.

tOdds ratios show a benefit for the antidepressant group.

\section{Data extraction}

Data extracted included symptoms, setting, treatment (regimens and follow up), patient characteristics, assessment of comorbid psychiatric disease, adverse effects, outcomes, and statistical analysis of reported results. Reviewers independently assessed the quality of study methods by using the Jadad scale.

\section{Main results}

94 RCTs on 6 symptom syndromes met the selection criteria. 6595 patients ( $76 \%$ women) were studied for a median of 9 weeks. The overall mean quality score was 4.8 (maximum score 8 ). The dropout rate was $>20 \%$ in $40 \%$ of the RCTs. A meta-analysis of 48 RCTs combined results for improvement in any of the following outcomes: global assessment (patient or physician), summary symptom index scores, or pain severity scale scores (table). 4 patients (95\% CI 3 to 7 patients) would need to be treated to improve 1 additional patient's condition. A meta-analysis of the results for continuous outcomes reported a pooled standardised mean difference of 0.87 (CI 0.59 to 1.14), which is equivalent to a greater improvement for the average patient treated with antidepressants than for $\{81 \% \text { (CI } 72 \% \text { to } 87 \% \text { ) }\}^{*}$ of the patients in the placebo group.

\section{Conclusion}

In patients with unexplained physical symptoms or syndromes, antidepressants are effective for improving outcomes, including symptoms and disability.

*Numbers calculated from data in article.

\section{COMMENTARY}

Patients with MUPS are common in primary and secondary care. Increasing evidence exists that psychological treatments such as cognitive behaviour therapy (CBT) are effective in the treatment of such symptoms. ${ }^{12}$ Unfortunately, suitably trained therapists are scarce, and psychological treatment is unacceptable to some patients with MUPS. Thus, effective pharmacological treatments have a potentially substantial role in the treatment of patients with MUPS.

The review by O'Malley et al supports the use of antidepressants in the treatment of a range of MUPS. The number needed to treat of 4 for short term improvement is clinically significant and is similar to that obtained with CBT. ${ }^{12}$ Importantly, it does not seem to be necessary to be depressed to benefit from "antidepressants," and people with a wide range of MUPS appear to benefit. An important caveat is that most evidence applies to patients in secondary care with chronic symptoms.

Clinicians therefore have 2 evidence-based treatment approaches for patients with MUPS: psychological (CBT) and pharmacological (antidepressants). If CBT is available, there is little to choose between it and antidepressants. The patient should therefore be encouraged to choose, because compliance with and enthusiasm for the chosen treatment may profoundly influence outcome. The person with MUPS who rejects psychological treatment, however, may also reject the use of antidepressants for "physical" problems. The term "antidepressants" is unhelpful in this situation and is increasingly inappropriate as evidence for other indications accumulates.

Several further decisions face the clinician. Firstly, which antidepressant? No convincing evidence exists for 1 group. Secondly, what dose? Little evidence is available although, as the therapeutic action appears independent of antidepressive action, low doses may be effective. Finally, for how long? Antidepressants are effective treatments for people with MUPS over periods of weeks. Whether treatment can be withdrawn and the optimal duration of treatment are unclear, however. Several key knowledge gaps must therefore be addressed by further primary research. Until then, the clinician should consider prescribing antidepressants that are safe and well tolerated, with dose and duration determined empirically.

Jonathan Price, MA, MSc, MRCPsych University of Oxford Oxford, $U K$

1 Speckens AE, van Hemert AM, Spinhoven P, et al. Cognitive behavioural therapy for medically unexplained physical symptoms: a randomised controlled trial. BMJ 1995;311:1328-32.

2 Price JR, Couper J. Cognitive behaviour therapy for adults with chronic fatigue syndrome. (Cochrane Review, latest version 24 Sept 1999.) In: Cochrane Library. Oxford: Update Software. 